\title{
On the Tertiary genus Soudanella Apostolescu (1961) (Ostracoda, Crustacea)
}

\author{
RICHARD A. REYMENT and JOSEF F. ARANKI \\ Paleontologiska Institutionen, Uppsala Universitet, Box 558, S 75122 Uppsala, Sweden.
}

\begin{abstract}
The mainly Paleogene ostracod genus Soudanella Apostolescu (1961) is revised and quantitative aspects of its variability analysed by multivariate and geometric statistical methods. The role of ornamental polymorphism in the genus is considered, but dismissed on the weight of evidence, albeit indirect, for true specific identity of each of the three forms. The palaeo-biogeographical importance of Soudanella is reviewed.
\end{abstract}

\section{INTRODUCTION}

Apostolescu (1961, p.808) erected the genus Soudanella, referred to Brachycytherinae, for ostracods with a subtriangular to subvoidal carapace of medium size, massive, generally rather inflated and with feebly developed eye-tubercles, with or without an ocular indentation. The lateral ornament was described as being strongly costate, reticulated, or a combination of both and there is no sub-central tubercle. The hinge was said to be amphidont. In more detail, the hinge was characterized in the following terms: The right elements comprise a cylindrical anterior tooth, a comma-shaped postjacent socket, a crenulated median furrow and a reniform posterior tooth. The elements of the left valve complement those of the right valve. There are up to 40 sinuous radial pore-canals, some of which are bifurcated. The adductorial muscle field comprises four posterior scars and an anterior $v$-shaped one.

Apostolescu gave the type species as Soudanella laciniosa laciniosa Apostolescu (1961) from Bopa, Bénin (formerly Dahomey) and referred it to the Paleocene. The species was interpreted as encompassing three subspecies, namely, the typesubspecies, S. l. reticulata, from the Paleocene of Fresco, Ivory Coast, and S. l. triangulata, from the Paleocene of Sangalkam, Senegal.

Perusal of Apostolescu's (1961) illustrations yields some further interesting details that were not mentioned in the original descriptions, but which have taxonomical relevance. These are:

(1) In S.l. laciniosa there is a clearly incised furrow separating the lateral field of costations from the anterior zone of subtubercular swellings, the anterior margin is denticulated; the drawings of the internal characteristics of the shell (Apostolescu, 1961, pl.xvi, figs 304, 305) deviate from the descriptive text in respect of details of the hinge and the pattern of muscle scars.

(2) S.l. triangulata is not always easily separated from S. I. laciniosa on the basis of outline.

(3) S.l. reticulata has the same shape as S.I. laciniosa, as well as the sharply incised anterior furrow, and there is the same kind of ornament in the anterior zone, to wit, subtuberculate swellings.
Granted that the three taxonomical categories are geographically separated, it is quite likely that they are biologically defined subspecies, even separate species. A case will be made in the following for conferring full specific status on triangulata partly on the grounds of the markedly differing outline seen in many specimens. However, Nigerian material of Soudanella s.l. shows that there are occasional intergradations between trianguloid and ovoid outlines which suggests that the taxonomic distinctions would be difficult to maintain, if it were not for other quite substantial differences.

Apostolescu (1961, p.809) compared his genus with Protobuntonia and Buntonia. Reyment (1963) regarded Soudanella as synonymous with Protobuntonia. The present investigation has shown, however, that Soudanella should be maintained as a distinct genus which is probably not even closely related to Protobuntonia, the resemblance being due to homeomorphy.

The aim of the present note is to examine the range of variation of Soudanella and to analyse a possible speciation event in which S. laciniosa Apostolescu, or S. triangulata Apostolescu. arose from $S$. ioruba (Reyment) very early in the Paleocene (Danian). If such an event really did take place, it did so quite rapidly, as the time that would have been taken for the completed transition was well within the confines of the Danian.

All figured material is kept in the collections of the Palaeontological Museum, University of Uppsala.

\section{RESULTS OF SEM-ANALYSIS OF NIGERIAN MATERIAL} The SEM-analysis of the Nigerian material of Soudanella laciniosa leads to the following elaboration of the original description of the type species.

The anterior margin is distinctly denticulated, the posterior margin is sparsely denticulated. The eye-tubercles are not opposite and tend to be somewhat more strongly developed than originally stated. The anterior marginal zone is ornamented with six rectangular pits which are located between indistinctly swollen reticular walls. There are 13 longitudinal costae. The eye-sockets are well developed. The notching of the hinge-bar is variable, but never strong; it seems to be a primary feature. The posterior tooth 
of the right valve may be vaguely notched.

Under the assumption that the species encompasses two closely connected ornamental categories, the general properties of ornamental variation may be expressed as follows:

\section{Soudanella laciniosa}

The forma typica of the species as originally proposed by Apostolescu (1961). The lateral ribs are only occasionally bifurcated in both males and females. The ribs are narrow with broad intercostal areas. A second, more anteriorly located row of pits may occur, anterior to the marginal zone described in the foregoing section. Specimens of this species are illustrated in Plate 2, figs 1-3.

\section{Soudanella triangulata}

The ornament of the anterior zone is effaced or it may appear "smeared". The anterior furrow is always deeply incised. The posterior of the carapace is extended. The lateral ribbing is broader and flatter than in typical laciniosa but the number of costae is the same. Some individuals have lost the full lateral ornament and there are smooth centro-lateral fields. In Nigeria, the main occurrence of the triangulata-type is the Ilaro sequence. Examples of the species are shown in Plate 1, figs 1-4.

\section{Soudanella ioruba}

The ornamental properties of Soudanella ioruba are similar to those of $S$. laciniosa but there is a smooth anterior field and a significant size-difference. These differences are most clearly manifested in the morphometric analysis presented later.,

The costation is irregularly developed and consists of a variable number of ribs of varying length, ranging from 11 to occasionally 13 in number. Bifurcated ribs occur. There is a tendency to develop a smooth antero-central zone and the posterdorsal region can, in some specimens, resemble Buntonia in being truncated (acuminate). Specimens are illustrated in Plate 1, fig.5 and Plate 2, fig. 4 .

\section{STRATIGRAPHICAL RELATIONSHIPS}

One borehole is particularly instructive for exposing the timerelationships between species; this is the sequence penetrated at Gbekebo, western Nigeria. The essential features are summarized below, with the oldest level sampled in the borehole placed first in the sequence.

\section{Levels in feet}

$3253-3257$

$3227-3230$

$2921-2918$

$2835-2838$

$2733-2730$

\section{Taxa occurring}

S. ioruba

form possibly intermediate in some

characters between ioruba and laciniosa;

S. ioruba

laciniosa and triangulata

triangulata

laciniosa and triangulata

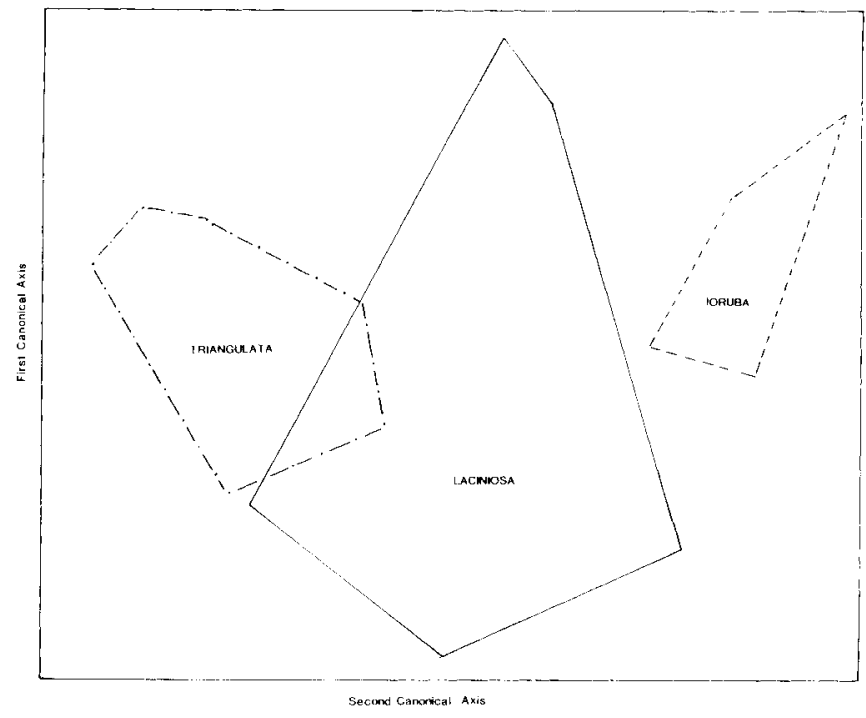

Fig.l. Schematic representation of the plot of the first two sets of canonical variate scores for all three samples. The fields occupied by the three sets of points are denoted by their convex hulls. Note the complete separation of the field for $S$. ioruba from those for $S$. laciniosa and S. triangulata which latter two overlap slightly.

The foregoing suggests that $S$. ioruba predates triangulata and laciniosa. Further information from two other boreholes indicates that $S$. laciniosa occurs exclusively at one site (Araromi), whereas $S$. triangulata is the only form found at the lime-rich site of Ilaro, some $150 \mathrm{~km}$ distant from Araromi and Gbekebo. A case could be made for the evolution of $S$. laciniosa - triangulata from $S$. ioruba and there are several indications that speak for this hypothesis. Firstly, the ornamental similarities point to a rather close relationship, secondly, some individuals of $S$. ioruba resemble the laciniosa-morphotype, whereas others are similar to the triangulata-morphotype. Thirdly, the stratigraphical ordering of the species is not in disagreement with such an event.

\section{EXAMINATION OF THE SPECIATION HYPOTHESIS}

A suitable starting point for examining the hypothesis of speciation is to assess the morphometrical relationships between the three categories. This can be appraised by a canonical variate analysis. For the purposes of this analysis, four commonly made measurements were used, namely, length of carapace, height of carapace, length of hinge, distance from anterior margin to the anterior furrow. The distances between the three canonical variate means for the three samples are approximately equal. It is clear that the samples are clearly different from each other. The plot of

\section{Explanation of Plate 1.}

Figs 1 a,b. Soudanella triangulata Apostolescu. Stereopair; left valve, SEM stub PM-B05. Ilaro borehole, depth $165 \mathrm{ft} . \mathrm{x} 130$.

Figs 2, a-b. Same species and provenance. Stereopuir of dorsal aspect SEM stub PM-BO5. x 125.

Fig.3. Same species and provenance. Internal aspect of a right valve showing hinge. SEM stub PM-BO5. x220.

Figs 4, a-b Same species and provenance. Stereopair of left hinge showing ocular tube. SEM stub PM-BO5. x220.

Figs 5, a-b. Soudanella ioruba (Reyment). Dorsal aspect of a left hinge. SEM stub PM-BO12. Gbekebo borehole, 3227-3232ft. x130. 

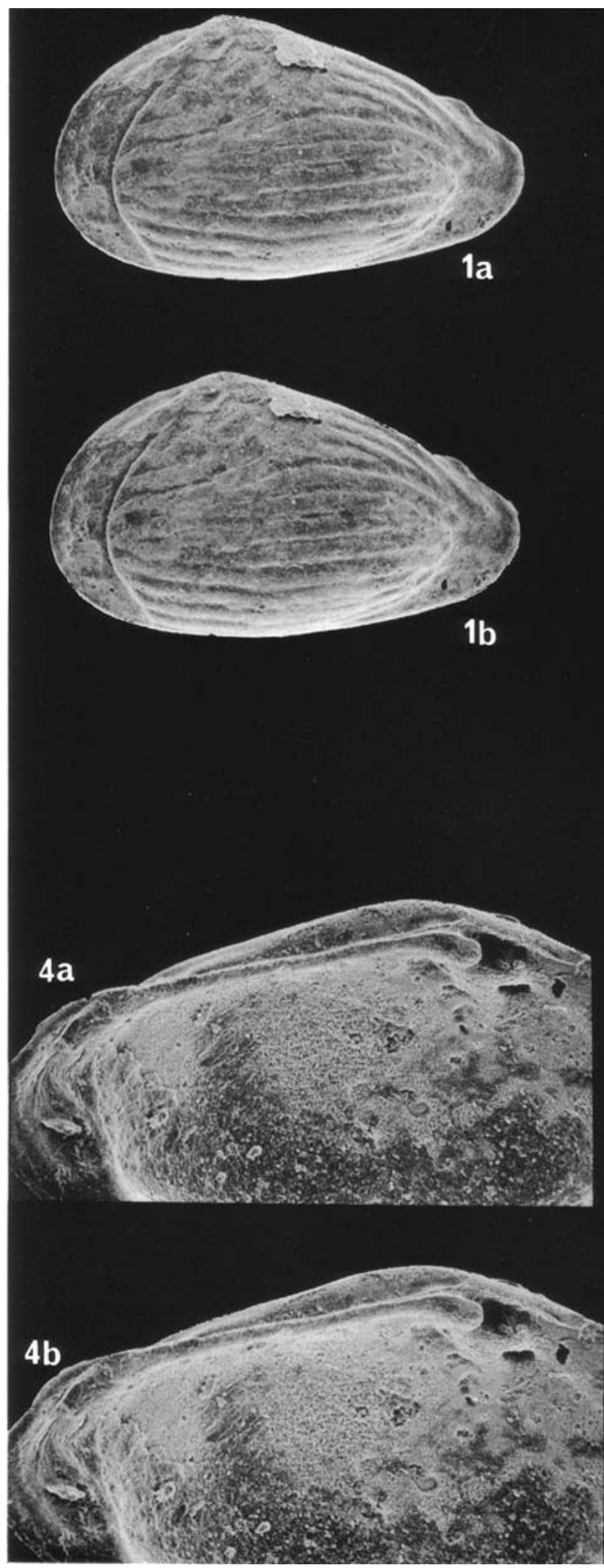
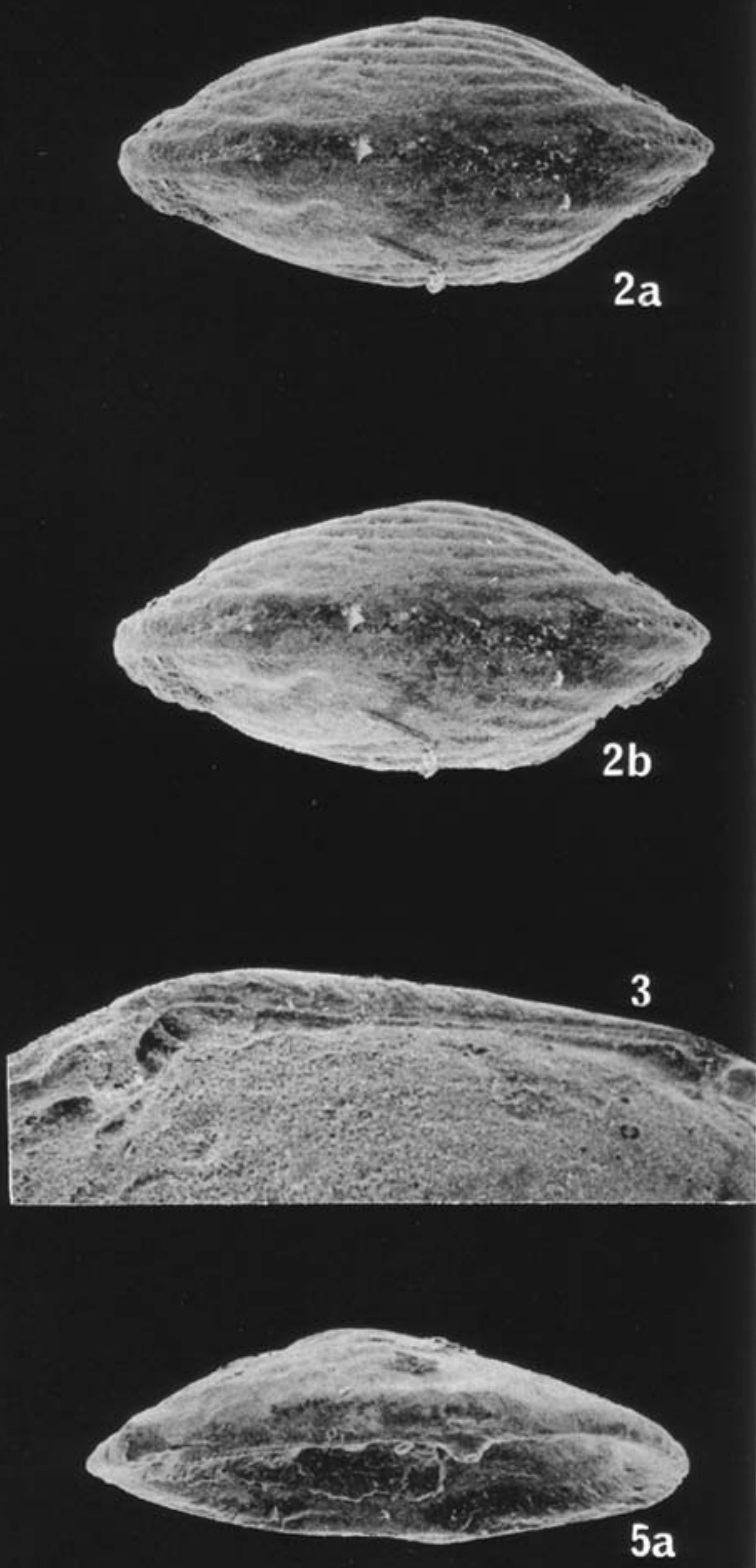

$5 a$

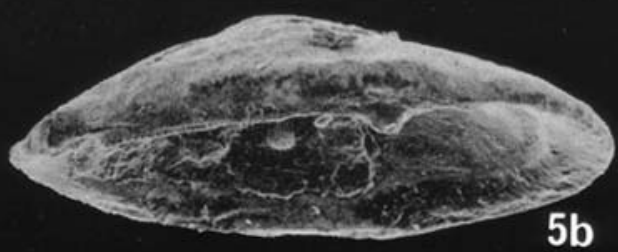




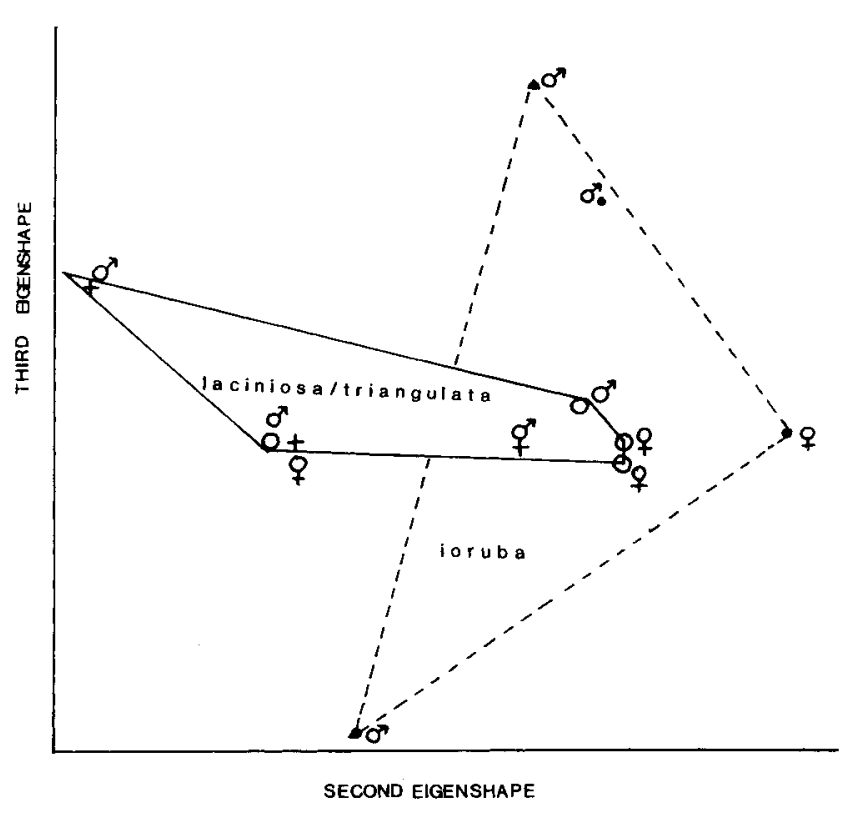

Fig.2. Plot of the second and third eigenshapes for the three sets of samples. Closed dots denote $S$. ioruba, crosses indicate $S$. laciniosa and circles $S$, triangulata.

the individual scores in the same plane, illustrated schematically in Fig.1 by the convex hulls for the points, shows that there is very little overlap between samples. The most immediate conclusion to be drawn from the results summarized in Fig. 1 is that there are marked size-differences between the three groups, with little overlap between them and that the two younger categories are significantly different from Sioruba.

Variation in the outline of the shell was studied by eigenshape-analysis (Lohmann, 1983). All possible combinations of axes were studied, most of which proved to be informative. Two of the pairs, found to be the most relevant to our study, are reported on here.

In the plane of the first and third eigenshapes, there is undoubted differentiation according to outline differences in that triangulata individuals group in a central cluster, together with some belonging to laciniosa. S. ioruba separates from the complex of laciniosa-triangulata. The plot in the plane of the second and third eigenshapes (Fig.2) supports that for the first and third eigenshapes in all essential details and also illustrates the morphometric closeness in laciniosa and triangulata. The analysis shows, therefore, that $S$. ioruba differs in outline from the pair S.laciniosaltriangulata.

The hypothesis of a possible speciation event can now be approached by means of examining its feasability in relation to the observed morphological differences in the four characters of interest in terms of (a) selection in the absence of random genetic drift, (b) random genetic drift in the absence of selection and, (c) random genetic drift in conjunction with selective effects. The method used for doing this is that of Lande (1976), applied to micropalaeontology by Reyment (1983). The mathematics used by Lande for his quantitative-genetic analysis are rather difficult. For the interested reader we can recommend an accessible account of the theory given by Manly (1985, p.359).

A rather simply composed analysis can be made in terms of upper and lower limits for the number of generations between sampling levels. Given that the event took place in the early Paleocene, and was terminated during this time-interval, and under the likely assumption that Soudanella produced one generation per year (this supposition is based on abundancies), a reasonable range for investigation lies between a maximum of one million years and a minimum of one hundred thousand years. The comparisons were made for a value of the heritability of 0.4 , which is a typical figure for characteristics such as shell-dimensions.

Under the maximum assumption, a case can only be made for selective effects for the passage of $S$. ioruba to $S$. laciniosa, in the absence of drift, with about one selective death per million individuals per generation and to engage, solely, the length of the carapace. This would be very feeble selection indeed. The selective effect for a transformation from $S$. ioruba to $S$. triangulata is more convincing; it, again, does not support a drifthypothesis.

Under the minimum assumption, the structure resident in the data become more evident. This is the natural mathematical outcome of the fact that the morphometrical distances between the four characters in the latter case are mostly greater for than for the former case (the exception is provided by the fourth character, the distance from the anterior margin to the anterior furrow). We summarize these results in Table 1.

It will be seen that most differentiation concerns length of the carapace, which may be a spurious effect due to unresolved sexual dimorphism. In this connexion we note that height, which is usually slightly, or not at all, touched by sexual dimorphic differences, is neutral for the ioruba-laciniosa-change. It is, however, a reasonable selective possibility for a transition from ioruba to triangulata.

In conclusion, we submit that although the present analysis is unable to provide unequivocal indications as to the validity of the speciation hypothesis examined here, it does, even on the basis of limited material, outline a possible path for such an event.

\section{PALAEOBIOGEOGRAPHICAL SIGNIFICANCE OF SOUDANELLA}

Neufville (1979) identified Soudanella laciniosa in borehole samples from the Paleocene of northeastern Brazil, the only record

Explanation of Plate 2

Figs 1, a-b.Soudanella laciniosa Apostolescu. Right side of male carapace. SEM stub PM-BO8. Araromi borehole, $1352 \mathrm{ft} . \mathrm{x} 115$.

Figs 2, a-b.Same species and provenance. Inner left valve of female showing hinge, ocular tube and pattern of adductorial scars. SEM stub BO8. $x 130$. Figs 3,a,b. Same species and provenance. Dorsal view of male specimen. SEM stub PM-BO8. x110.

Figs 4, a-b.Soudanella ioruba (Reyment). Right side of a carapace. SEM stub PM-BO-12. Gbekebo borehole, $3221-3224 \mathrm{ft} . \times 130$. 

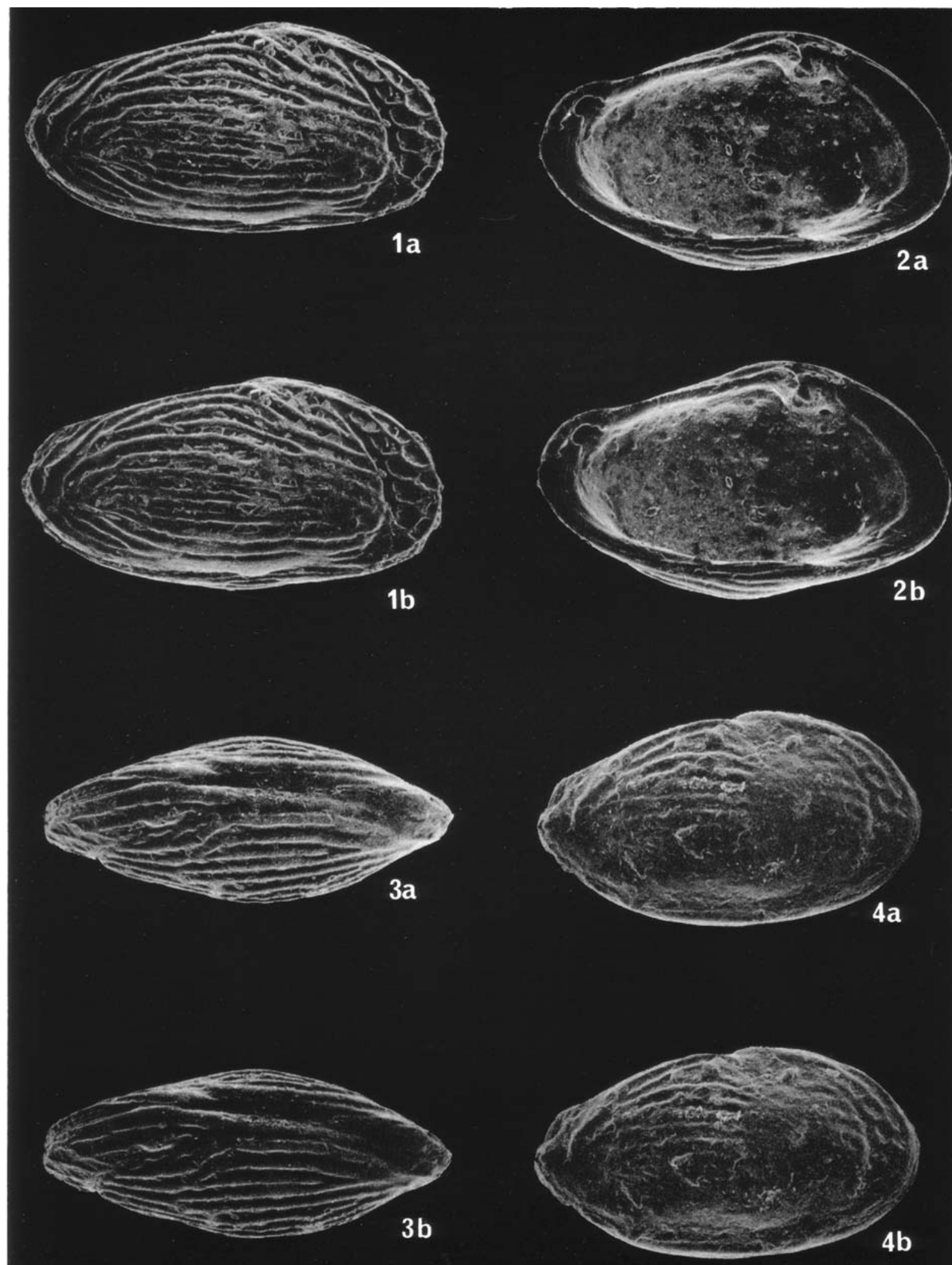
of this species outside of Africa. Stinnesbeck and Reyment (1988), using outcrop samples from the same area, were able to repeat Neufville's observations.

Reyment (1983), in a general survey of migrational routes in the South Atlantic during the Cretaceous and early Tertiary, noted particularly the remarkable distributional capabilities of some groups of ostracods. In addition to the case of S. laciniosa, there are also Togoina, an Eocene genus, and the Maastrichtian genus Nigeria, both of which are found in Argentina. Given that the South Atlantic was about half as wide in the Paleocene as it is loday, this is still a considerable distance for benthic ostracods to negotiate. Various mechanisms were suggested by Reyment (1983), including transport on algae and the possibility of "islandhopping" via the Walvis-Rio Grande link. In the former case, transport on drifting algae would presuppose the existence of a trans-Atlantic oceanic surface current in the Paleocene, similar to that existing today during a certain part of the year (Reyment, 1966).

Table 1. Hypotheses of selection in the absence of drift and vice versa for the averred transition from $S$. ioruba to S. laciniosaltriangulata.

$\begin{array}{lclr}\text { Character } & \begin{array}{c}\text { Selection: no } \\ \text { drift culled } \\ \text { gen } / 10^{6}\end{array} & \begin{array}{c}\text { Drift: no selection } \\ \text { minimum } \\ \text { population }\end{array} & \text { Comments } \\ \text { A. } & \begin{array}{c}\text { ioruba/laciniosa } \\ \text { L }\end{array} & 8 & 35000 \\ \text { H } & 0 & \text { unacceptably great } & \text { both feasible } \\ \text { not feasible } \\ \text { Hinge } & 5 & 88000 & \text { both feasible } \\ \text { Ant. furr. } & 2 & \text { unacceptably great } & \text { unlikely } \\ \text { B. } & \text { ioruba-triangulata } & \\ \text { L } & 21 & 6000 & \text { both feasible } \\ \text { H } & 5 & 68000 & \text { selection } \\ \text { Hinge } & 10 & 23000 & \text { both feasible } \\ \text { Ant. furr. } & 1 & \text { unacceptably great } & \text { unlikely } \\ \text { Ant. furr. } & 1 & \text { unacceptably great } & \text { unlikely }\end{array}$

\section{CONCLUSIONS}

Our analysis of available data on Soudanella indicates that the genus had a restricted existence in early Paleocene time. It displayed a remarkable ability to migrate, having reached Brazil from West Africa, and formed part of the impressive ostracod migration between North Africa and West Africa (Barsotti, 1963; Reyment and Reyment, 1981). What seem to be genuine representatives of the genus have been recorded from the Neogene of Senegal and Guinea-Bissau (Carbonel, 1986) and a new species was recently erected by Carbonnel and Johnson (1989) for a form from beds in Togo, attributed to the Eocene.

Although the data are insufficient to allow a completely rounded treatment of the problem, we have been able to demonstrate that there is a reasonable chance of Soudanella ioruba having formed the parent species for S. laciniosa and $S$. triangulata. All three species have ornamental and shape characteristics in common. We are unable to propose an ancestral lineage for Soudanella; a case could possibly be made for Protobuntonia, but there is no evidence for this known to us.

From the purely technical point of view, the mathematical techniques we have employed in our study interweave geometric morphometrics and standard distance-based multivariate morphometrics, a union that proved to be rewarding.

\section{ACKNOWLEDGEMENTS}

The SEM photography was carried out by Eva Reyment, Uppsala. The research was mainly done while Reyment was the recipient of a guest-professorship at the University of Bonn, Germany.

Manuscript received October 1989

\section{Revised Manuscript accepted October 1990}

\section{REFERENCES}

Apostolescu, V. 1961. Contribution à l'étude paléontologique (Ostracodes) et stratigraphique des bassins Crétacés et Tertiaires de l'Afrique Occidentale. Revue Institut français du Pétrole, 16, 779-867.

Barsotti, G. 1963. Paleocenic ostracods of Libya (Sirte Basin) and their wide distribution. Revue Institut français du Pétrole, 18, 1520-1528.

Carbonnel, G. 1986. Ostracodes tertiaires (Paléocène à Néogène) du bassin sénégaloguinéen. Documents Bur. rech. geol. min., 101, 33-243.

Carbonnel, G. and Johnson, A, 1989. Les Ostracodes paléogènes du Togo: taxonomie, biostratigraphie, apports dans l'organisation et l'évolution du bassin. Geobios, 22, 409-443.

Lande, R. 1976. Natural selection and random genetic drift in phenotype evolution. Evolution, 30, 314-334.

Lohmann, G.P. 1983. Eigenshape analysis of microfossils: A general morphometric procedure for describing changes in shape. Mathematical Geology, 15, 659-672.

Neufville, E.M.H. 1979. Paleogene ostracods from northeastern Brazil. Bull. geol. Insin Univ. Uppsala, NS 8, 135-172.

Manly, B.F.J. 1985. The Statistics of Natural Selection. Chapman and Hall, London. $\mathrm{xvi}+484 \mathrm{pp}$.

Reyment, R.A. 1963. Studies on Nigerian Upper Cretaceous and Lower Tertiary Ostracods. 2: Danian, Paleocene and Eocene Ostracoda.Stockholm Contr. Geol. 7 , 1-238.

Reyment, R.A. 1966. Studies on Nigerian Upper Cretaceous and Lower Tertiary Ostracoda. 3: Stratigraphical, biometrical and paleoecological conclusions. Stockholm Contr. Geol., 14, 1-151.

Reyment, R.A. 1983. Phenotypic evolution in microfossils. Evolutionary Biology, 16, 209-254.

Reyment, R.A. and Reyment, E.R. 1981. The Paleocene trans-Saharan transgression and its ostracod fauna. Second Conference on the Geology of Libya, Tripoli (1978), Vol.1, 245-254, Academic Press, London.

Stinnesbeck, W.S. and Reyment, R.A. 1988. Note on a further occurrence of Soudanella laciniosa Apostolescu in northeastern Brazil. Journal of African Earth Sciences, 7, 779.781. 